\title{
Convergence in Green Growth as the Key to Fighting Climate Change, 1990-2019
}

\author{
Małgorzata Porada Rochoń
}

check for updates

Citation: Porada Rochoń, M. Convergence in Green Growth as the Key to Fighting Climate Change, 1990-2019. Energies 2021, 14, 8324 https://doi.org/10.3390/en14248324

Academic Editors: Luisa F. Cabeza, Wen-Hsien Tsai and

Radoslaw Miskiewicz

Received: 25 October 2021

Accepted: 1 December 2021

Published: 10 December 2021

Publisher's Note: MDPI stays neutral with regard to jurisdictional claims in published maps and institutional affiliations.

Copyright: (C) 2021 by the author. Licensee MDPI, Basel, Switzerland. This article is an open access article distributed under the terms and conditions of the Creative Commons Attribution (CC BY) license (https:// creativecommons.org/licenses/by/ $4.0 /)$.
Institute of Economics and Finance, University of Szczecin, 70-453 Szczecin, Poland; Malgorzata.porada-rochon@usz.edu.pl

\begin{abstract}
The consequences of climate change are an important point of contention in the current policy debate on the sustainability of economic development and growth. Climate change contributes to many socio-economic disadvantages and risks. The primary objective of global policy 2050 is to fully understand the negative externalities of environmental change. Goal and methodology: the main goal of the study is to examine convergence to the steady green growth state for a sample of 130 countries from 1990 to 2019 . Setting up an efficient and consistent policy to fight climate change demands empirical knowledge on green growth. Using log $(t)$ test methodology, we investigate convergence in green growth indicators for selected samples based on available country data. Findings: our assumptions are: (1) economies are not motivated and eager to foster energy transition; instead, they accept it as a random policy goal and (2) economies want to foster energy transition, but they are limited by a significant trade-off factor pulling their efforts down. Convergence testing shows the existence of two significant convergence clubs, one with countries moving to energy transition and the second still promoting national output based on fossil fuels. The findings indicate future divergence between the two clubs and significant convergence within identified convergence clubs. Conclusions: the energy transition is moving forward at two-tier speed with green leaders and green follower clubs. Policymakers and practitioners must closely monitor the dynamics of green growth to assess the risk and uncertainties of climate change.
\end{abstract}

Keywords: convergence; green growth; climate change; sustainability; energy transition

\section{Introduction}

There is still discussion about the ideal standard metric for comparing countries' progress on a global scale. Alternative socio-economic well-being indicators are not mutually exclusive and can be used simultaneously, mainly to mitigate the risks associated with a gross domestic product (GDP) being used as a proxy for well-being [1].

One key issue is how to quantify green growth (Stjepanović, S.; Tomić, D.; Škare 2017, 2019) [2]. Currently, many indices aim to better combine economic, political, social, and environmental ambitions to identify potential synergies, trade-offs, and prospects targeting the green economy and growth. Unfortunately, these current single-digit, internationally calculated aggregate indices are not applicable unless several indicators are constrained in a single comprehensive assessment.

The use of critical facts and data to monitor development will not answer the path to green growth. Without effective measurement methods and sufficient statistics, the valuation of the green economy is subject to subjective consideration. Measurement of a company's "green performance" requires reliable statistical data. The process of collecting vital information to monitor progress and evaluate results is exacerbated by the lack of widely accepted methodological guidelines. Instead of waiting interminably for statistical designs from relevant global subjects (top-down approach) and accounting contributions (bottom-up approach) to develop into internationally known and accepted methods, we seek to exploit their economic potential fully. Although many believe that this problem 
is too broad, [1] argues that calculating a green indicator, more precisely, a green gross domestic product (green GDP), is possible and should be investigated [2].

The convergence of the per capita ecological footprint using annual data for the European Union countries from 1961 to 2013 was examined by (Ulucak and Apergis, 2018) [3]. They found the presence of a few convergence clubs within the EU's per capita ecological footprint. Similar research was performed by (Bilgili and Ulucak, 2018) [4]. Authors demonstrated the convergence in the ecological footprints of G20 countries between 1961 and 2014. Convergence dynamics in $\mathrm{CO}_{2}$ intensity for the EU-28 countries from 1990 to 2016 in the work of (Emir et al., 2018) [5], are isolated in five to seven clubs (EU-28), three to five (EU-15 and EU-new). Finally, research by (Haider and Akram, 2019) finds that two distinct steady states (club convergence) exist in a sample of 77 nations from 1961 to 2014 [6].

Presno et al., 2021 [7], in the period 1990-2017, demonstrated that the hypothesis of convergence in the greenhouse gas emissions index is rejected. On the contrary, the United Kingdom, Germany, Belgium, Sweden, Denmark, and ex-communist countries cut their emissions more than the UE-28 average.

The analysis of the literature reveals a gap in the convergence theme as well as the novelty of the issue. Past research has focused on national, regional, or countries' associations to estimate convergence in $\mathrm{CO}_{2}$, greenhouse gas emissions, renewable resource use, and consumption. Looking at fossil fuels consumption or renewable resource use separately from national output gives us no insights into "green" growth. Sustainable development must be addressed by considering both development (GDP) and sustainability (Green GDP). On the other hand, taking energy transition and production (output dynamics) will leave us at the starting point.

The Global Green Growth Institute has developed a composite index to provide policy makers with a benchmark for decision-making. Simply called the Green Growth Index (GGI), it assesses the performance of 115 countries in four dimensions of green growth (efficient and sustainable resource use, protection of natural capital, green economic opportunities, and social inclusion) using 36 indicators, all of which are highly relevant indicators for tracking progress toward Sustainable Development Goals, the Paris Climate Agreement, and the Aichi biodiversity targets (GGGI, 2019) [8].

Green GDP is a term that refers to various adjusted gross domestic product measures that have been adjusted to social and environmental costs; therefore, Green GDP is simply another way to quantify and measure the monetary impact of social and environmental damage caused by economic growth in a country. Stjepanović, Tomić, and Škare (2017) [2] provided an intriguing explanation for the indicator's conceptual purpose.

The purpose of our study is to contribute to the theoretical and empirical knowledge on "green" growth dynamics by looking at the convergence in green growth indicators for a sample of 130 countries from 1990 to 2019. By doing this our study contributes to the efforts to fight climate change.

The numer of countries was limited by data, limited time period data, and the lack of widely accepted methodological guidelines.

To estimate convergence in green growth for the countries in the sample (selected on data availability), we follow [9-11]. We can identify steady states in green growth and isolate convergence clubs with member countries using the above-developed methodology.

We examine the convergence of green growth indicators for a sample of economies using data from the OECD's growth indicators database. We are looking for indications of significant convergence in indices (natural resource base, resource productivity, socioeconomy, environmental quality of life, policy, and finance) of green growth. A high degree of convergence would imply a collective pattern in the world's energy transition, identifying green leaders and followers. Green growth involves promoting economic growth and development, while ensuring that natural resources and environmental services necessary for human well-being continue to be provided (OECD, 2014, 2017, 2021) [12-15]. 
The following sections comprise the remainder of the article: to begin, a conceptual framework is offered that explains the importance of measuring and understanding convergence in green growth indicators, namely green growth and green GDP. Following that, the methodologies utilized to investigate the hypothesized existence of green growth convergence, the level of convergence, and the number of convergence clubs are presented. The study's findings are subsequently presented. Finally, the article finishes with a description of the study's contribution to research and future directions for research on green growth and sustainability.

\section{Materials and Methods}

This article examines convergence and convergence clubs' green growth using annual data from 1990 to 2019 for a sample of 130 countries. Convergence clubs consist of countries sharing the same steady-state dynamics in green growth indicators. The study's primary database is the OECD. Stat Green growth indicators [12-15]. The OECD Green Growth Database offers a selection of indicators to monitor progress toward green growth, to inform policymakers and the public. The database compiles data and indicators from various areas, including the OECD databases and external data sources. In addition, the database includes OECD member and accession countries, essential partners (such as Brazil, China, India, Indonesia, and South Africa), and other non-OECD countries selected for inclusion. The country selection was limited on the OECD database we used in our analysis. The OECD methodology deals with the problem of differences between Eu countries and ex-communist countries as it is defined in their study and reports. Sample selection for countries was based on ranking provided by the OECD green indicators database corrected for possible sample bias. The list of countries in the sample is available at https: / / www.oecd.org/greengrowth/green-growth-indicators / (accessed on 25 January 2021).

The indicators were selected using well-defined criteria and placed in a conceptual framework, which is structured in four groups that represent the most critical characteristics of green growth: natural assets base, environmental dimension (quality of life), economic opportunities and policy response, and environmental and resource productivity. The database contains data on green economic growth (natural capital in use increasing efficiency), natural assets base condition (resource degradation), quality of life (environmental), and the effectiveness of green growth policies. The data are provided as production-based $\mathrm{CO}_{2}$ productivity (GDP per unit energy-related $\mathrm{CO}_{2}$ emissions) in USD (2015 prices) per kilogram in annual terms. The production-based $\mathrm{CO}_{2}$ productivity (GGDP) is used to determine a country's green growth level. The economic value generated per unit of $\mathrm{CO}_{2}$ emitted is measured by production-based $\mathrm{CO}_{2}$ productivity. The term "production-based emissions" refers to the direct $\mathrm{CO}_{2}$ emissions from fossil fuel combustion that occur within a country's borders. They are not inclusive of bunkers, sinks, or indirect effects.

The rationale and theoretical foundation for utilizing (GGDP) as a measure of a country's green production (green growth) are to assess if registered output growth (real GDP) is becoming "greener". Not only is the evidence for this rationale scarce, but it is also missing evidence on green growth convergence. Actual growth may become "greener," but the fact we should look into it is twofold. First, who are the countries becoming "greener" and why and second, is there a convergence (in clubs) across countries, or green growth is a divergent function. Here we study green growth convergence among 130 nations, using the definition of green growth indicators [14]. Apart from the results, it is important to study other green growth indices' convergence. These benchmarks provide information about a country's success in energy transition, but they cannot be used to forecast future events or determine a country's green growth.

The determinant-oriented approach [16] assumes a correlation between specific determinants and a country's competitiveness; the inference is that they are interrelated and linked to green growth. A location's cost is determined by various factors, including production elements, labor, capital, technology, infrastructure, and business circumstances. 
While this strategy is advantageous for understanding the causes and determinants of competitiveness, it ignores technological gaps. For example, in 1990, former communist countries were technologically 20-30 years behind market economies (innovation and technological advancement). They use a determinant-oriented approach and overlook this reality of considerable technical divergence resulting in a green growth convergence bias when measuring green growth. As a result, and because the primary objective is to assess convergence and convergence clubs in green growth, we chose a result-based approach to convergence testing rather than to investigate green growth determinants.

Green GDP should not be confused with other social and environmental accounting systems, as many of them have value and calculation concerns [12], Despite numerous indicators of sustainable socio-economic growth that track the economic, social, and environmental dimensions of development, there is no consensus on the optimal standard metric that would enable countries to compare progress at the global level. Some alternative indicators of socio-economic well-being, which start with national accounting and GDP, and then add or eliminate key aspects, could be considered measures that solve some of the difficulties raised by the Green GDP indicators. Most of them are designed to mitigate the risks inherent in using GDP as a proxy for well-being. Although these indicators have inherent disadvantages (inadequate consensus, subjectivity, depreciation calculation), they are not mutually exclusive and can be applied simultaneously. form:

Convergence testing on green growth follows the paradigm proposed by [9-11] in the

$$
\log G_{i t}^{o}=\delta_{i t}^{o} \log G_{t}^{o}+e_{i t}
$$

where $\log G_{i t}^{o}$ is GDP per unit energy-related $\mathrm{CO}_{2}$ emissions in USD 2015 prices (GGDP) per kilogram in annual terms for the $i$ th country. $\log G_{t}^{o}$ as common (GGDP) trend across countries with idiosyncratic technology cycle components $e_{i t}$. Testing the null hypothesis of no convergence in green growth follows

$$
\begin{gathered}
\log \left(\frac{H_{1}}{H_{t}}\right)-2 \log \{\log (t)\}=a+b \log (t)+\varepsilon_{t} \\
\quad \text { for } t=[r T]_{1}[r T]+1, \ldots, T \text { with } r>0
\end{gathered}
$$

for details on convergence testing and proofs, see [9-11].

The pooled sample of countries (selection) is based on data available on green growth. Countries that have data in the OECD green growth indicators database are selected and included in the sample.

For details (assumptions and validations) on the methodological procedure [17] and tests for convergence to form green growth convergence clusters, see [9-11]. We follow the above procedure and classify countries according to their initial green growth indicators (GGDP). To set up the final convergence clubs, we use a $t$-test on all pairs of initial convergence clubs, invalidating the $t$-test for all pairs of initial convergence clubs.

Equation (3) takes the form

$$
H_{t}=N^{-1} \sum_{i=1}^{N}\left(h_{i t}-1\right)^{2} \rightarrow 0, t \rightarrow \infty
$$

The data on (GGDP) entered into the $t$-test are prefiltered using the [18]. To correct for possible bias in the smoothing parameter (annual data) we follow [17,18].

$$
\underset{\{g t\}_{t-1}^{T}}{m}\left\{\sum_{t=1}^{T}\left(y_{t}-g_{t}\right)^{2}+\lambda \sum_{t=1}^{T}\left[\left(g_{t}-g_{t-1}\right)-\left(g_{t-1}-g_{t-2}\right)\right]^{2}\right\}
$$

We determine cross-sectional means between convergence clubs by plotting relative transition curves between clubs. Plots show a trend of convergence or divergence in and between clubs [8]. 


\section{Results}

This is the first study to examine the convergence of green indicators, green growth, and the identification of green convergence clubs using the Philips approach $(2007,2009)$ to determine green growth convergence.

In this study, we check for the convergence in green growth indicators for selected economies with available data from the OECD growth indicators database. This study's assumption is that green growth is divergent for the whole sample with distinct green growth clubs. We are looking for evidence of strong convergence in green growth indicators. Strong convergence evidence would indicate a collective pattern in the world's energy transition. Such data offer no evidence on the speed or sustainability of energy transition dynamics. However, they tell us a similar pattern and dynamics in energy transitions across countries and regions. For such a case, finding just a few convergence clubs could indicate that countries are not interested or somehow limited in pursuing energy transition. Our assumptions are: (1) economies are not motivated and eager to foster energy transition; instead, they accept it as a random policy goal, and (2) economies want to foster energy transition, but they are limited by a significant trade-off factor pulling their efforts down. For any of the above assumptions to hold, we should find strong convergence in green growth. If this is not the case it would mean that some countries are more or less motivated to foster energy transition or are more or less limited by some unknown exogenous factor. For strong convergence in green growth to hold, we need test results supporting divergence in green growth, divergence in relative transition parameters resulting in five or more different convergence clubs and members.

However, this is not the case, and we find statistically significant evidence of a strong convergence pattern in green growth indicators. The $\log (t)$ regression coefficient, standard errors, and $t$-statistics are listed in Table 1.

Table 1. Green growth indicators, change in the natural log convergence club classification (GGDP).

\begin{tabular}{ccccc}
\hline \multicolumn{2}{c}{ Initial } & Test of Club Merging & \multicolumn{2}{c}{ Final } \\
\hline \multirow{2}{*}{ Club 1 (112) } & 0.242 & & Club 1 (112) & 0.242 \\
& $(0.043)$ & & \multirow{2}{*}{ Club 2 (18) } & $-0.043)$ \\
\hline \multirow{2}{*}{ Club 2 (18) } & -0.118 & Club 1 + 2 & & $(0.017)$ \\
\hline
\end{tabular}

Source: authors' research.

Since the $t$ statistics for (GGDP) are less than the test statistics $(t<-1.65)$, the null hypothesis of sample convergence in innovation is rejected at the $5 \%$ level for the entire sample. Test statistics for the sample report $t$-stat -2.43 ( 0.0225 standard errors $)$ and coefficient -0.0547 with $t$ statistics below the -1.65 threshold rejecting the hypothesis of sample convergence in green growth. We find no evidence to support the hypothesis of green growth convergence across the entire sample (130 countries). There are significant differences in the green growth dynamics of the countries and groups of countries included in the sample. We proceed with convergence clubs identification with $\log t$ regression results in Table 1.

According to the regression results (convergence test modeling), we identify two convergence clubs that hold for the green growth convergence hypothesis. Table 1 summarizes convergence clubs and countries identified based on the log t-test results for the (GGDP) indicator (log $t$-test results and club identification results).

From Table 1, we observe a strong convergence pattern in green growth from 1990 to 2019. Initial green growth convergence clubs identified by the log $(t)$ test list two convergence clubs and one non-convergent group. After testing for club merging properties, the final convergence list includes two different convergence clubs and zero non-convergent groups. 
Final convergence clubs' lists:

Convergence Club 1: Democratic Republic of the Congo, Ethiopia, Switzerland, Sweden, Sri Lanka, Cameroon, Myanmar, Tanzania, Côte d'Ivoire, Paraguay, Singapore, Costa Rica, Eritrea, Uruguay, Nigeria, Zambia, Cuba, Sudan, Panama, Kenya, Ghana, Malta, Ireland, Angola, France, Denmark, Gabon, Colombia, Albania, Norway, Guatemala, Iceland, Togo, United Kingdom, Latvia, El Salvador, Dominican Republic, Bangladesh, Austria, Peru, Mozambique, Italy, Romania, Philippines, Spain, Luxembourg, Nicaragua, Portugal, Brazil, Croatia, Hungary, Namibia, Mauritius, Turkey, Belgium, Armenia, Senegal, Slovak Republic, New Zealand, Indonesia, Netherlands, Finland, Germany, Tajikistan, Pakistan, Georgia, Azerbaijan, Haiti, Egypt, Yemen, Slovenia, Honduras, Mexico, Israel, Chile, Botswana, Ecuador, Argentina, Cyprus, Thailand, Congo, Greece, Tunisia, Japan, Morocco, North Macedonia, Lebanon, United States, Czech Republic, Moldova, Jordan, Poland, Jamaica, India, Malaysia, Bulgaria, Zimbabwe, Belarus, Korea, Australia, Qatar, Canada, Iraq, Serbia, Ukraine, Russia, Uzbekistan, China (People's Republic of), Kazakhstan, Mongolia, Syrian Arab Republic, Turkmenistan.

Convergence Club 2: Benin, Equatorial Guinea, Bolivia, Brunei Darussalam, Algeria, Venezuela, United Arab Emirates, Vietnam, Saudi Arabia, Kyrgyzstan, Bahrain, Kuwait, Iran, Libya, Oman, Bosnia and Herzegovina, Trinidad and Tobago, South Africa.

The countries are listed in the convergence clubs and displayed in charts for the purpose of observing green growth convergence dynamics. Figure 1 displays the initial clubs' green growth convergence relative transition path with two clubs. After testing for club merging, we find two convergence clubs and zero non-convergent groups.

\section{Club 1}

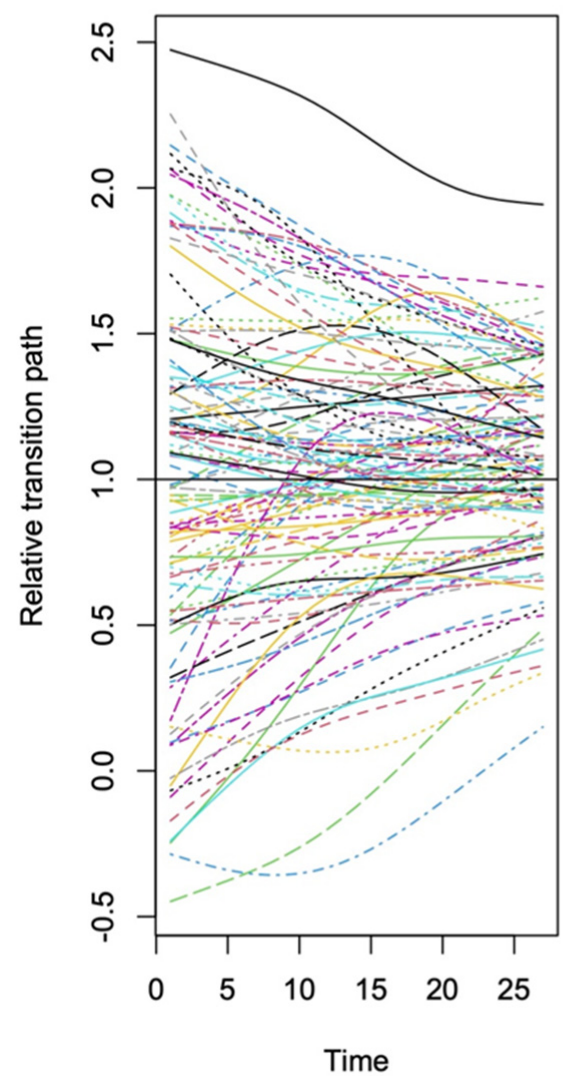

Club 2

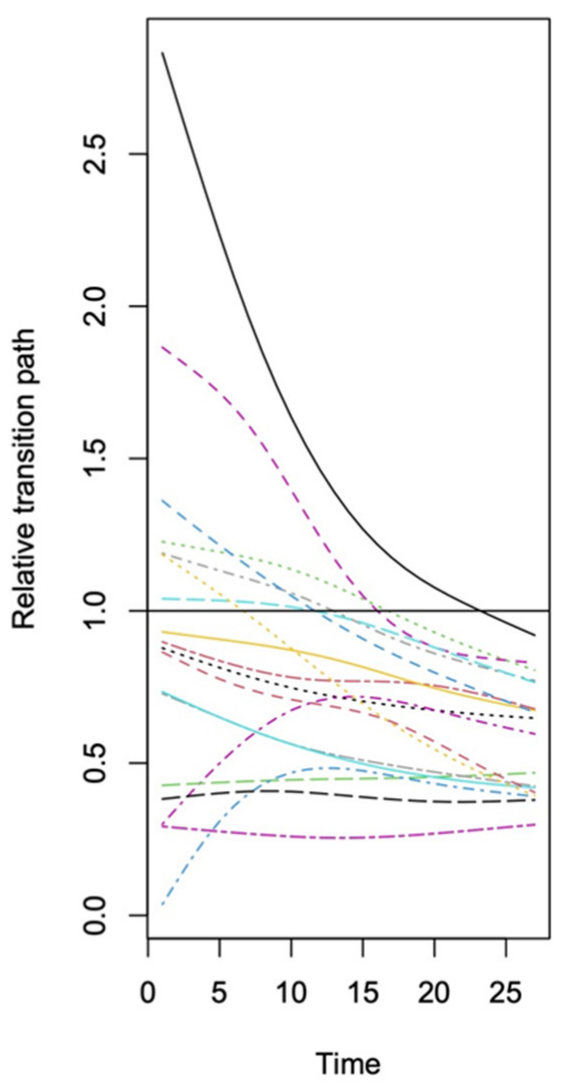

Figure 1. Relative transition path (clubs 1 and 2). Source: authors' research. 
We can observe a strong convergence pattern in green growth for convergence Club 1. Estimated relative transition curves strongly converge to a single point (hit $=1$ for all $i$, as $t$ approach infinity with $t$ measured in years). Relative transition parameters converging to a single point (unity) prove green growth convergence hypothesis holds (ultimate convergence). Relative convergence (relative transition parameters moving close but differing from unity) is visible for convergence Club 2. For the countries in Club 2, we still observe green growth convergence hypothesis holds but not as strongly as in the case of Club 1. The same result is visible when comparing average relative transitional curves for Club 1 and 2 (Figure 2).

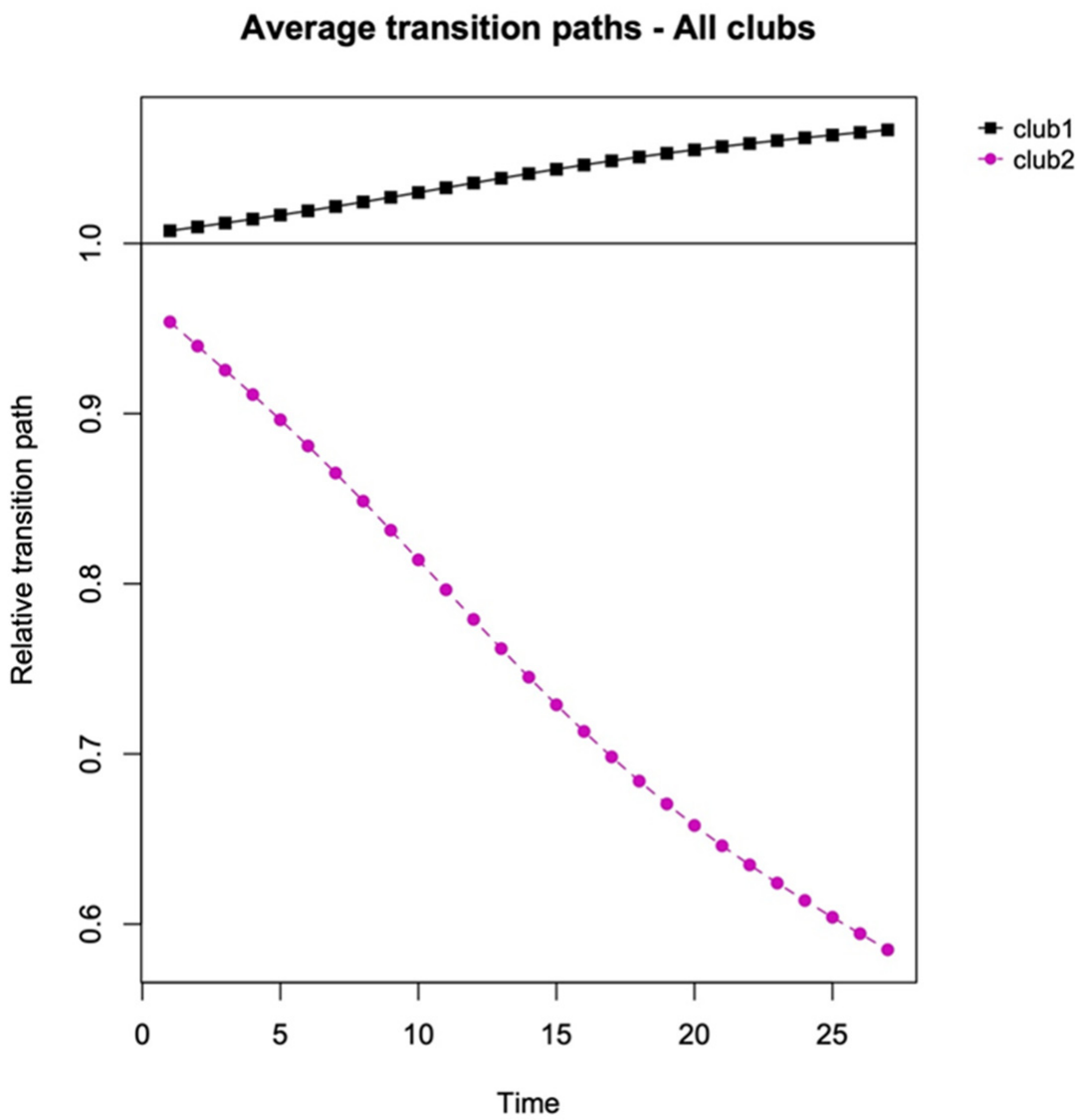

Figure 2. Average transition paths for Club 1 and Club 2. Source: authors' research.

We can notice ultimate green growth convergence for Club 1 as previously explained (average transition path close to unity). For the second convergence club, the average relative transition paths are declining, still supporting the convergence hypothesis in green growth (Club 2). Figure 3 displays an apparent convergence in relative transition path (country and average) and the difference in green growth convergence between the two clubs. Figure 2 lists countries sharing the same green growth convergence.

Study results show green growth (among the countries in the sample) is characterized by two distinct steady-state paths (two convergence clubs with each separate steady state). Thus, our results support the hypothesis of converging pattern to a common (green growth) production-based $\mathrm{CO}_{2}$ productivity (GGDP) level. Club 1 lists the countries that have the same dynamics of convergence in green growth. 

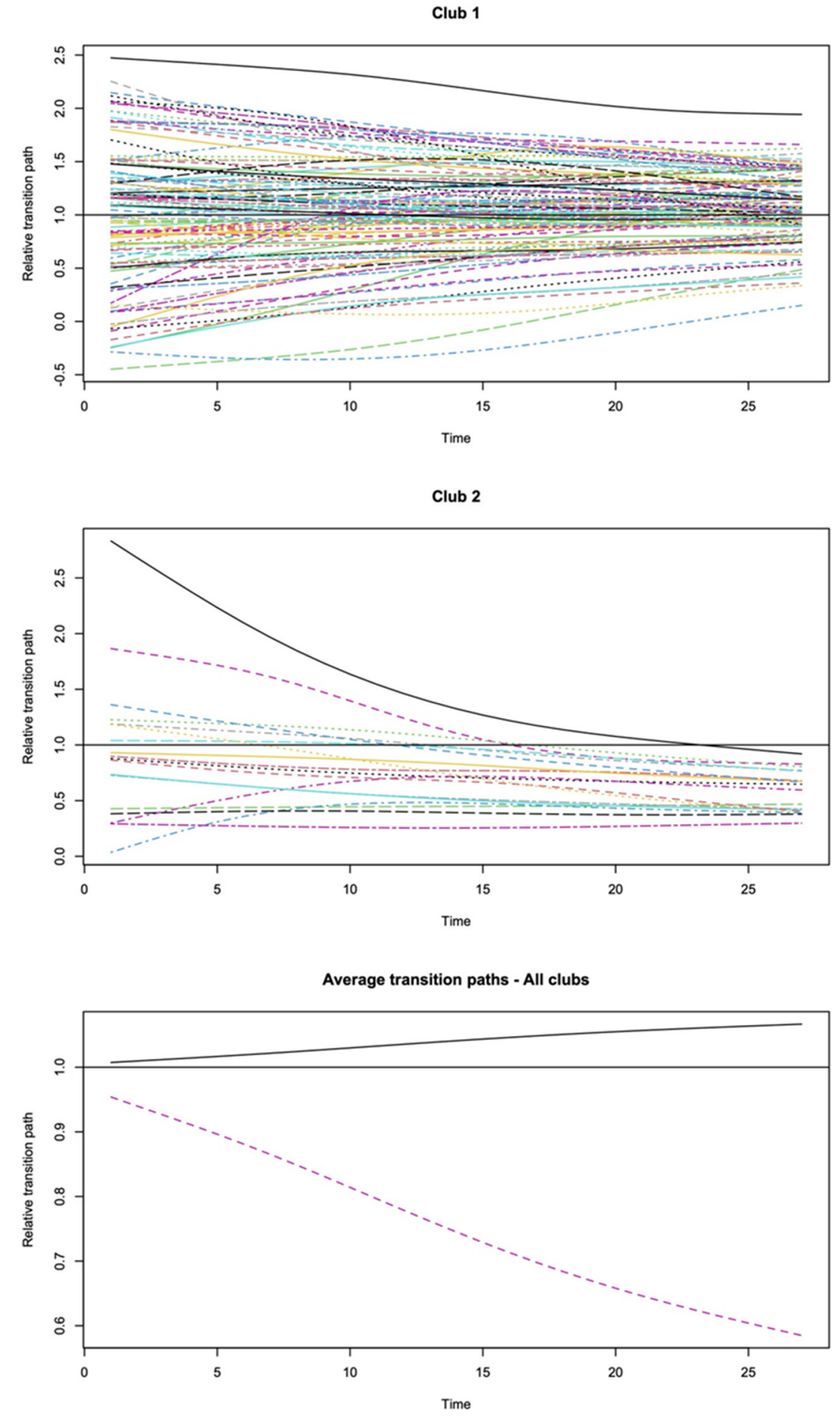

Figure 3. Convergence in relative transition path (country and average). Source: authors' research.

\section{Discussion}

Is the World Becoming a "Greener" Place?

From the results reported here, we can observe that countries in the sample produce more value-added per unit of energy-related $\mathrm{CO}_{2}$ emission. Such evidence supports the hypothesis of a World becoming a "greener" place in the last thirty years. A positive sign is to see China in the same green growth convergence club with advanced and world growth frontiers economies such as India, Brazil, and Malaysia. Countries falling behind, trying to establish energy transition are countries in Club 2. Club 2 is dominated by fossil 
fuel-dependent countries, rich in oil and heavily relying on oil-generated output. Therefore, countries listed in Club 2 represent a smaller share of the world's output, supporting the thesis of the world becoming a "greener" place.

This study presents new and unique research on green growth indicators across nations and times, allowing various stakeholders to address various green and development economic concerns. The socio-economic and environmental components of a country should be comparable to other countries in the region or in the world. These results provide accurate data that complement existing global databases by offering cross-country comparisons and comprehensive country coverage. The findings also contain important cross-county convergence empirics on green growth dynamics. It can therefore give a full picture of green economic objectives. As long as these findings are consistent across countries, it can serve as a tool for assessing sustainability concerns across economic and social programs. This provides a reliable point of study reference. Our study is unique in that it bridges the gap in economic research by providing quantitative knowledge and dynamic view on convergence in green growth.

We use different econometric approaches to ensure the model's best fit and robustness to check for possible issues in estimation results. We use three different, fully efficient estimation techniques following (Phillips, 2007-2009), (Sichera and Pizzuto, 2019) [19]. The results from all three robustness tests supports the results presented in this study.

Our results are in line with the study of [3]. They investigated the convergence of the per capita ecological footprint. The research was performed between 1961 to 2013 using the annual data for the case of the European Union countries. Supporting our results, the authors highlight a small number of convergence clubs in the per capita ecological footprint within EU countries. Another study by [4] shows the existence of the ecological footprint convergence among G20 countries over 1961-2014. We can find convergence properties in $\mathrm{CO}_{2}$ intensity for EU-28 countries from 1990 to 2016 in the study of [5] isolating five to seven clubs (EU-28), three to five (EU-15 and EU-new). Close, similar results to the one in our study with two different steady states (club convergence) are present in the sample of 77 countries over 1961-2014, as we can see in [7].

A study by [6] finds that the hypothesis of convergence in the greenhouse gas emissions index is rejected for 1990-2017. Among the countries that reduced their emissions above the UE-28 average were the United Kingdom, Germany, Belgium, Sweden, Denmark, and ex-communist countries.

\section{Conclusions}

The relationship between energy and growth is a hotly debated issue. Until recently, studies on this issue focused on the relationship between carbon emissions and economic growth, electricity's effects [20], and renewable energy's growth effects. Understanding the role of energy in economic growth is crucial for policymakers and practitioners preparing for the energy transition. In addition, economic growth models and strategies must be flexible enough to adapt to changing environmental conditions. This requires developing a new quantitative understanding of the relationship between economic growth and renewable energy.

We examine the convergence of green growth indicators for a sample of economies, using data from the OECD's Growth Indicators Database. The premise of the study is that green growth is different in each sample, characterized by discrete green growth clubs. We are looking for evidence of high convergence in green growth indicators. Convergence evidence is strong, which implies a collective pattern in the global energy transition. These results give no indication of the speed or viability of energy transfer dynamics. However, it shows a pattern and dynamics common to energy transitions in countries and regions. In this case, the presence of only a few convergence clubs may imply that countries are uninterested or constrained in the transition to energy. Our underlying assumptions are that (1) economies are not driven or eager to support energy transition; rather, they view it as a random policy objective, and (2) economies want to promote energy transition but are 
constrained by a significant trade-off component. To make one of the above assumptions true, we should observe significant convergence in green growth. If this is not the case, it implies that some countries are driven to promote the transition to energy or are constrained by an unknown exogenous factor. To maintain high convergence in green growth, we need test results showing divergence in green growth, in particular divergence in relative transition parameters, which leads to five or more distinct convergence clubs and members. This is not the case, as we find statistically significant evidence of strong convergence in green growth indicators.

Our paper focuses on measuring green growth convergence for 130 countries from 1990 to 2019. We find empirical evidence on strong convergence in green growth among selected countries in the sample. Two different convergence clubs emerge from the empirical analysis in this study. That is evidence of similar dynamics in energy transition across countries. The second convergence clubs list countries rich in oil with national output depending significantly on fossil fuel-based production. We see evidence of similar energy transition dynamics and patterns in most countries, revealing that the world is becoming greener. The issue is the speed of energy transition. Is the convergence speed to the "green" steady state sufficient to achieve energy transition and meet global measures and targets adopted to fight climate change? A transition (convergence) to a green economy is underway, but is the transition speed adequate? That is a question further studies on convergence and green growth should focus on. Here we supply empirical evidence on green growth convergence that future research could use to investigate convergence speed against a set agenda on sustainable development and climate change. The speed of convergence will tell us if the world's global attempt on planet decarbonization will be successful or not. To this end, we encourage future studies on the issue.

Funding: This research received no external funding.

Institutional Review Board Statement: Not applicable.

Informed Consent Statement: Not applicable.

Data Availability Statement: Skare, Marinko; Małgorzata Porada Rochoń, (2021), Convergence in green growth as Key to Fight Climate Change 1990-2019", Mendeley Data, V1, doi:10.17632/r2p9wdsp9j.1 (accessed on 25 January 2021).

Acknowledgments: I wish to thank Marinko Škare, University of Pula, Croatia for valuable comments and suggestions in managing and setting data model framework.

Conflicts of Interest: The author declares no conflict of interest.

\section{References}

1. Boyd, J. Nonmarket benefits of nature: What should be counted in green GDP? Ecol. Econ. 2007, 61, 716-723. [CrossRef]

2. Stjepanović, S.; Tomić, D.; Škare, M. A new approach to measuring green GDP: A cross-country analysis. Entrep. Sustain. Issues 2017, 4, 574-590. [CrossRef]

3. Ulucak, R.; Apergis, N. Does convergence really matter for the environment? An application based on club convergence and on the ecological footprint concept for the EU countries. Environ. Sci. Policy 2018, 80, 21-27. [CrossRef]

4. Bilgili, F.; Ulucak, R. Is there deterministic, stochastic, and/or club convergence in ecological footprint indicator among G20 countries? Environ. Sci. Pollut. Res. 2018, 25, 35404-35419. [CrossRef] [PubMed]

5. Emir, F.; Balcilar, M.; Shahbaz, M. Inequality in carbon intensity in EU-28: Analysis based on club convergence. Environ. Sci. Pollut. Res. 2018, 26, 3308-3319. [CrossRef] [PubMed]

6. Haider, S.; Akram, V. Club convergence analysis of ecological and carbon footprint: Evidence from a cross-country analysis. Carbon Manag. 2019, 10, 451-463. [CrossRef]

7. Presno, M.J.; Landajo, M.; González, P.F. GHG emissions in the EU-28. A multilevel club convergence study of the Emission Trading System and Effort Sharing Decision mechanisms. Sustain. Prod. Consum. 2021, 27, 998-1009. [CrossRef]

8. GGEI. 2018 Global Green Economy Index. Green Policy Platform. Available online: https://www.greengrowthknowledge.org/r esearch/2018-global-green-economy-index-ggei (accessed on 9 December 2020).

9. Phillips, P.C.B.; Sul, D. Transition Modeling and Econometric Convergence Tests. Econometrica 2007, 75, 1771-1855. [CrossRef]

10. Phillips, P.C.; Sul, D. Some empirics on economic growth under heterogeneous technology. J. Macroecon. 2007, 29, 455-469. [CrossRef] 
11. Phillips, P.C.B.; Sul, D. Economic transition and growth. J. Appl. Econom. 2009, 24, 1153-1185. [CrossRef]

12. OECD. Towards Green Growth: Monitoring Progress. 2011. Available online: https://doi.org/10.1787/9789264111356-en (accessed on 25 January 2021).

13. OECD. Green Growth Indicators 2014. Available online: https://doi.org/10.1787/9789264202030-en (accessed on 25 January 2021)

14. OECD. Green Growth Indicators 2017. Available online: https://doi.org/10.1787/9789264268586-en (accessed on 25 January 2021)

15. OECD. Stat. Green Growth Indicators. OECD. Stat. Available online: https://stats.oecd.org/Index.aspx?DataSetCode=GREEN_ GROWTH\# (accessed on 23 September 2021).

16. Hildebrandt, A.; Antoinette, M. The Competitiveness Challenge: EU Member States in International Trade. Monet. Policy Econ. 2007, 4, 67-88.

17. Hodrick, R.J.; Prescott, E.C. Postwar U.S. Business Cycles: An Empirical Investigation. J. Money Credit Bank. 1997, 29 , 1-16. [CrossRef]

18. Hamilton, J.D. Why You Should Never Use the Hodrick-Prescott Filter. Rev. Econ. Stat. 2018, 100, 831-843. [CrossRef]

19. Sichera, R.; Pizzuto, P. ConvergenceClubs: A Package for Performing the Phillips and Sul's Club Convergence Clustering Procedure. R J. 2019, 11, 142. [CrossRef]

20. Qerimi, D.; Dimitrieska, C.; Vasilevska, S.; Alimehaj, A. Modeling of the Solar Thermal Energy Use in Urban Areas. Civ. Eng. J. 2020, 6, 1349-1367. [CrossRef] 